\title{
The Self-reported Health of Immigrant Groups in Switzerland
}

\author{
Alexander Bischoff · Philippe Wanner
}

Published online: 16 October 2007

(C) Springer Science+Business Media, LLC 2007

\begin{abstract}
Background: More than 20\% of people living in Switzerland are immigrants, defined as people with foreign nationality. This study examines health disparities between the main immigrant groups in Switzerland and the majority Swiss population. Methods: Epidemiological analysis of the 2002 Swiss Health Survey (SHS): the SHS contains health-related information about 19,706 people who were randomly sampled from among people living in Switzerland. Bi-variate and multivariate analyses of six variables on self-reported health were performed. Findings: The data from the 2002 Swiss Health Survey provide some evidence of health disparities between Swiss people and immigrants. Although the self-reported health of "Northern immigrants" (people from Germany and France) does not differ significantly from that of the majority Swiss population, "Southern immigrants" (people from Italy, Former Yugoslavia, Portugal, Spain and Turkey) report lower levels of health in several areas. Lower levels of health are particularly likely to be reported by Italian men and women. Conclusion: The self-reported health of immigrants is currently inferior to that of the Swiss. If it is the position of the Swiss health care system to ensure equal health provision for all Swiss residents, including immigrant groups, and to strive for equal health outcomes for all, self-reported ill health among immigrants is a useful basis for health policy and planning.
\end{abstract}

\footnotetext{
A. Bischoff ( $\square)$

Institute of Nursing Science, University of Basel,

Bernoullistrasse 28, 4056 Basel, Switzerland

e-mail: alexander.bischoff@unibas.ch

P. Wanner

Laboratory of Demography, University of Geneva,

Geneva, Switzerland
}

Keywords Migration · Self-reported health $\cdot$ Switzerland

\section{Introduction}

Demographic changes in European populations over the last 50 years are characterized by two main aspects: aging and-equally important-migration. Migratory movements have led to the formation of pluralistic societies. Switzerland is a case in point. It has one of the highest immigration rates in Europe. In 2002, more than $20 \%$ of people living in Switzerland are immigrants, defined as people with a foreign nationality [1].

Of the 1.5 million immigrants in Switzerland, 22\% are Italian, $14 \%$ are from Former Yugoslavia (Serbia-Montenegro, Bosnia-Herzegovina, Kosovo), $10 \%$ are Portuguese, $8 \%$ are German, $6 \%$ are Spanish, $6 \%$ are Turkish and $4 \%$ are French. The remaining $30 \%$ of immigrants are made up of smaller groups of other nationalities.

In recent years, there has been increasing awareness of health disparities between the majority populations and minority (immigrant) groups in the European and North American countries. Research has shown that some immigrant and minority groups differ in health status, health-seeking behaviour and access to health care [2-5].

Health-related disparities between nationals and immigrant groups have also been documented in Switzerland. The 1992/1993 Swiss Health Survey [6] showed, for example, that the immigrant population tended to suffer more from ill health than Swiss nationals. The data showed clear differences between the two groups. Apart from a few somatic diseases which were more common among the immigrant population (TB, poor pregnancy outcomes, occupational health problems), the main differences were found in the area of mental health. These included feeling "mentally not well" 
and lacking a sense of mastery (one's capability of problemsolving and mastering his/her own). Within some immigrant communities a more fatalistic attitude was found towards whether people could influence their own health. The evidence also suggested that in relation to health behaviour, problems of overweight, poor eating habits and lack of physical exercise were more common in immigrants [7]. In another study, some immigrant groups showed worse health outcomes than others [8].

These data as well as other empirical data were used to develop a nation-wide policy on immigrant health [9]. However, because the sample sizes of individual immigrant groups were too small to identify statistically significant differences in their health status, it was not possible to differentiate between the different groups. In the 2002 Swiss Health Survey, sample sizes were increased. This made it possible to interview representative proportions of the main immigrant groups [10].

The current study uses the SHS 2002 data gained from the interviews to compare the self-reported health and illhealth status of the main immigrant communities in Switzerland with that of the majority Swiss population.

\section{Methods}

\section{The Swiss Health Survey}

The aim of the Swiss Health Survey (SHS) is to investigate health status and its determinants, the socio-medical consequences of ill health, and health care utilization in a representative sample of the resident population of Switzerland [11]. To date the survey has been carried out three times, in 1992/93, 1997 and 2002. The 2002 SHS data contain information about 19,706 people living in private households who were interviewed by telephone (CATI, Computer Assisted Telephone Interviewing). In 205 cases, face-to-face interviews were organised (mainly with older people). In the case of long-term absence of a (sampled) person, a proxy interviewee was requested (947 cases). The interviews were carried out in German, French or Italian. People who did not speak any of these three languages were excluded from the survey. Other criteria for exclusion were: asylum seeker status, households without a telephone, very poor health status and living in a nursing home [10]. Following the sampling, data was weighted according to age, gender, nationality (Swiss, foreign), and canton of residence (16 groups) in order to achieve a representative result [12].

Data were de-identified. We obtained permission to analyse and publish the data via contract \# 04/100/05.04.04 (title: "towards improving outcomes for migrant patients with chronic illness") with the Swiss Federal Statistical Office.
Immigrant Groups

Immigrant groups are defined on the basis of nationality. Seven immigrant groups, in each of which 70 or more respondents were interviewed, were included in the analyses. These were, in order of sample size (large to small): Italians, Germans, people from Former Yugoslavia (including Serbs, Montenegrinians, Croats, Bosnians, Kosovaris and Macedonians-all labelled "Yugoslavs" in this study), Spaniards, Portuguese, French, and Turks. Immigrant groups in which fewer than 70 people were interviewed were excluded from the data analyses. Thus, out of a total of 19,706 valid data sets, 457 were excluded, leaving a sample of 19,249 subjects.

\section{Variables}

Six health-related variables were considered in the data analyses. These indices (as they are labelled in the SHS) are compound variables that draw on several other variables. They include: a history of symptoms of chronic conditions; lack of mental wellbeing; lack of a sense of mastery; physical inactivity; and overweight (BMI). Table 1 provides details of these variables. All these variables were dichotomised (see logistic regression analyses). Because dichotomisation implies a loss of detail in the analyses, we tried alternative polytomic logistic regressions with health variables that can be ordered. The models did not yield differences in the significance levels.

\section{Data Analysis}

In the first part of the findings, the health-related variables are presented in cross-tabulations. All analyses were carried out separately for men and women. Statistical significance was measured by Mann-Whitney tests. In the second part of the findings multivariate analyses were performed. The covariates included in the regression models were: nationality, age, education, socio-professional status, and income. These are shown in logistic regression tables displaying the Odds Ratios (OR) with the respective confidence intervals and the $p$-values. Analyses were run using SPSS and SAS.

\section{Findings}

The findings are presented in three parts: (1) sociodemographic characteristics, (2) dependent variables on self-reported health (reporting of chronic symptoms, lack of mental wellbeing, lack of mastery, lack of physical activity and overweight) with the results of men and women presented separately, and (3) multivariate analyses. In the last section each of the different immigrant groups is discussed in turn. 
Table 1 Indices of self-reported health (SHS 2002)

\begin{tabular}{|c|c|c|c|}
\hline Indices & Specifics & Categories & Dichotomisation \\
\hline Symptoms & $\begin{array}{l}\text { Definition: Presence of chronic } \\
\text { symptoms over the last four } \\
\text { weeks prior to the interview } \\
\text { Constructed from symptoms } \\
\text { including } \\
\text { Backache } \\
\text { Weakness } \\
\text { Abdominal pain } \\
\text { Digestive troubles } \\
\text { Diarrhoea or constipation } \\
\text { Sleeping troubles } \\
\text { Headache } \\
\text { Remark: Symptoms do not include } \\
\text { fever }\end{array}$ & $\begin{array}{l}1=\text { no or very few symptoms } \\
2=\text { slight symptoms } \\
3=\text { severe symptoms }\end{array}$ & $\begin{array}{l}0=\text { no symptoms or very few } \\
\text { symptoms } \\
1=\text { slight or severe symptoms }\end{array}$ \\
\hline $\begin{array}{l}\text { Lack of mental } \\
\text { wellbeing }\end{array}$ & $\begin{array}{l}\text { Definition: feeling mentally unwell } \\
\text { Constructed from variables } \\
\text { including } \\
\text { Upset } \\
\text { Undisturbed } \\
\text { Irritable } \\
\text { Energetic }\end{array}$ & $\begin{array}{l}1=\text { poor } \\
2=\text { fair } \\
3=\text { good }\end{array}$ & $\begin{array}{l}0=\text { good or fair } \\
1=\text { poor }\end{array}$ \\
\hline Mastery & $\begin{array}{l}\text { Definition: lack of mastery } \\
\text { Constructed from variables } \\
\text { including } \\
\text { Heavy problems } \\
\text { Little control } \\
\text { Tossed about (hin und } \\
\text { hergerissen) }\end{array}$ & $\begin{array}{l}0=\text { low level of mastery } \\
1=\text { intermediate level of mastery } \\
2=\text { high level of mastery }\end{array}$ & $\begin{array}{l}0=\text { intermediate or high level } \\
\text { of mastery } \\
1=\text { low level of mastery }\end{array}$ \\
\hline $\begin{array}{l}\text { Physical } \\
\quad \text { inactivity }\end{array}$ & $\begin{array}{l}\text { Definition: lack of physical } \\
\text { activity in leisure time } \\
\text { Constructed from variables } \\
\text { including } \\
\text { Lack of physical activity } \\
\text { with sweating during leisure } \\
\text { Frequency of this activity } \\
\text { per week }\end{array}$ & $\begin{array}{l}0=\text { no physical activity } \\
1=\text { once or twice per week } \\
2=\text { three times per week or more }\end{array}$ & $\begin{array}{l}0=\text { physical activity: } \\
\text { once or more per week } \\
1=\text { no physical activity }\end{array}$ \\
\hline BMI & $\begin{array}{l}\text { Definition: Obesity according } \\
\text { to Body mass index } \\
\text { Constructed from variables } \\
\text { including } \\
\text { Weight } \\
\text { Size }\end{array}$ & $\begin{array}{l}1=\mathrm{BMI}<20 \\
2=20 \leq \mathrm{BMI}<25 \\
3=25 \leq \mathrm{BMI}<30 \\
4=30 \leq \mathrm{BMI}\end{array}$ & $\begin{array}{l}0=\mathrm{BMI}<30 \\
1=\mathrm{BMI} \geq 30\end{array}$ \\
\hline
\end{tabular}

Socio-demographic Characteristics

\section{Gender}

There are higher proportions of men in the Italian, Yugoslav, Spanish and French groups than in the Swiss, German, Portuguese and Turkish groups (cf. Table 2).
Age

The Yugoslav, Spanish, Portuguese and Turkish groups have the highest proportion of young people (15-34 years old). The Italian, German, French and Swiss groups all have similar proportions-about 30\%-of young people (15-34 years old). The proportion of elderly people 


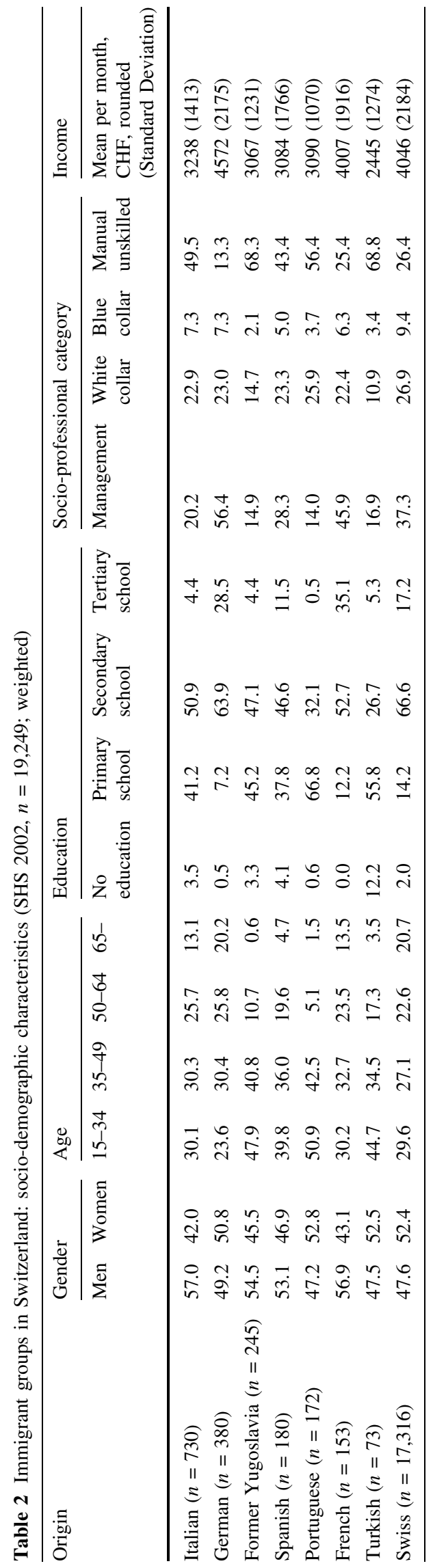

( $>65$ years) in the Swiss group is $21 \%$ (with similar proportions in the German and French groups); the proportions of elderly people in the other groups are substantially lower.

\section{Education and Socio-professional Categories}

There are clear differences in educational level among the different groups. The proportions of those with tertiary education are highest in the French, German and Swiss groups; they are lowest in the Italian, Yugoslav, Portuguese and Turkish groups. Similar patterns can be observed in the four socio-professional categories: The Swiss, German and French groups have the largest proportion of people working in the highest (management) category; there are very few managers among the other immigrant groups. It is noteworthy that the proportions of highly educated and managerial German and French people are significantly higher than among the Swiss population.

\section{Income}

There is a marked difference in income between the higher-income "Northern Europe" group (Swiss, German and French) and the lower-income "Southern Europe" group which contains the remaining immigrant groups. Within the "Southern Europe" group, the Spanish are the highest paid, followed by the Italians, people from Former Yugoslavia and the Portuguese, and finally, with a considerable gap, the Turks. In the multivariate analyses, the five socio-demographic variables are always included in the logistic regression models (see below).

\section{Self-reported Physical Symptoms}

\section{Men}

Half of the men in the Swiss reference group, and similar proportions of German, Yugoslav and French men, reported that they had suffered from physical symptoms over the previous 4 weeks (cf. Fig. 1). Almost $60 \%$ of Italian men, and similar proportions of Turkish and Portuguese men, reported having suffered physical symptoms in the same period. Spanish men were the least likely to report having suffered physical symptoms. However, none of the differences between these groups reaches statistical significance $(p=0.08)$.

\section{Women}

Two-thirds of the women in the Swiss reference group, and similar proportions of German, Yugoslav and French 
Fig. 1 Frequency distributions of self-reported chronic symptoms, by origin and sex (SHS 2002)

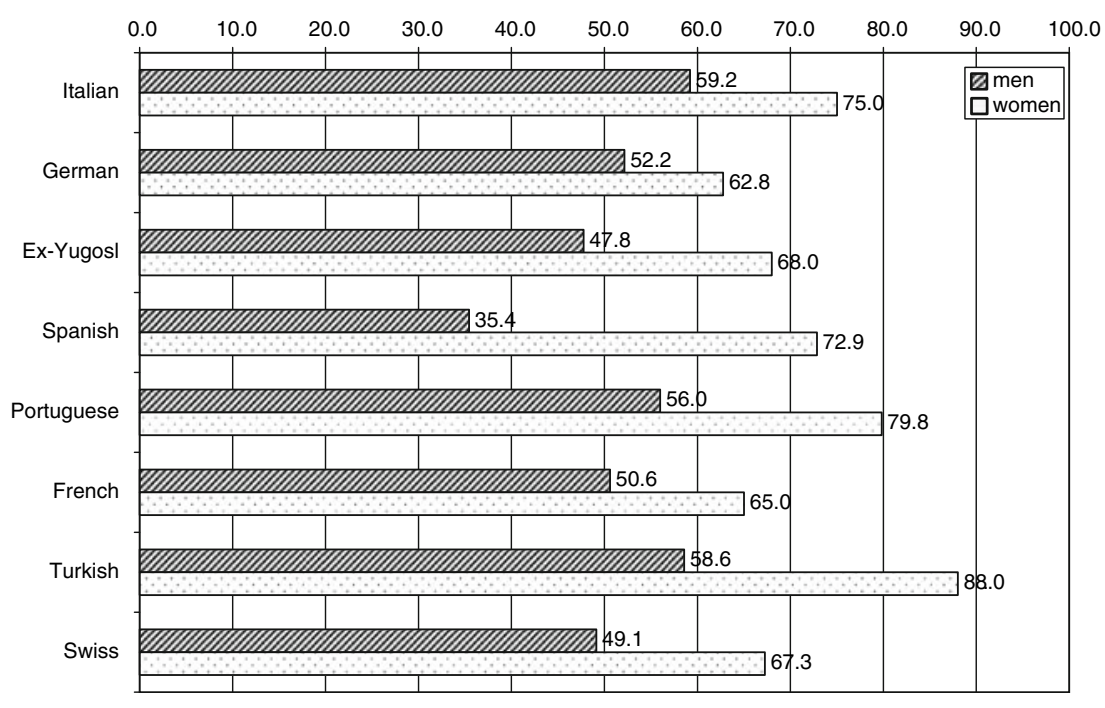

women, reported that they had suffered from physical symptoms over the previous 4 weeks (cf. Fig. 1). Higher proportions of women in the Turkish, Portuguese, Italian and Spanish groups reported having suffered symptoms of chronic conditions in the same period. All these differences are statistically significant at a level of $p=0.03$. It is noteworthy that in all the groups more women than men reported that they had suffered from physical symptoms over the previous 4 weeks.

\section{Lack of Mental Wellbeing}

\section{Men}

The proportion of men reporting a lack of mental wellbeing was lowest in the Spanish group, followed by the Swiss reference group. Higher proportions of men in all the other groups reported a lack of mental wellbeing: (from highest to lowest) Turks, Germans, French, Portuguese, Italians, and men from Former Yugoslavia (see Fig. 2). All these differences are statistically significant at a level of $p=0.002$.

\section{Women}

The proportion of women reporting a lack of mental wellbeing was lowest in the German and French groups and in the Swiss reference group. The proportions in all the other groups were higher: (from highest to lowest) Turks, Spanish, Yugoslavs, Italians and Portuguese. Here too, the differences between the groups are significant at a level of $p<0.001$.
Fig. 2 Frequency distributions of reported 'lack of mental wellbeing", by origin and sex (SHS 2002)

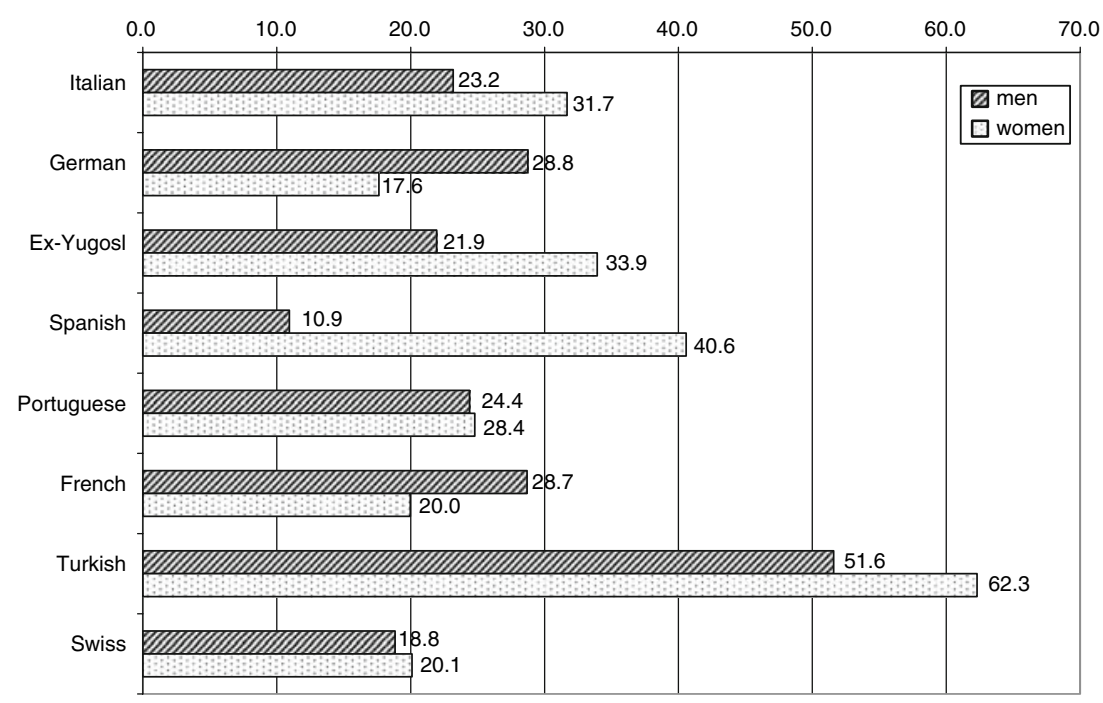


Fig. 3 Frequency distributions of reported "lack of mastery", by origin and sex (SHS 2002)

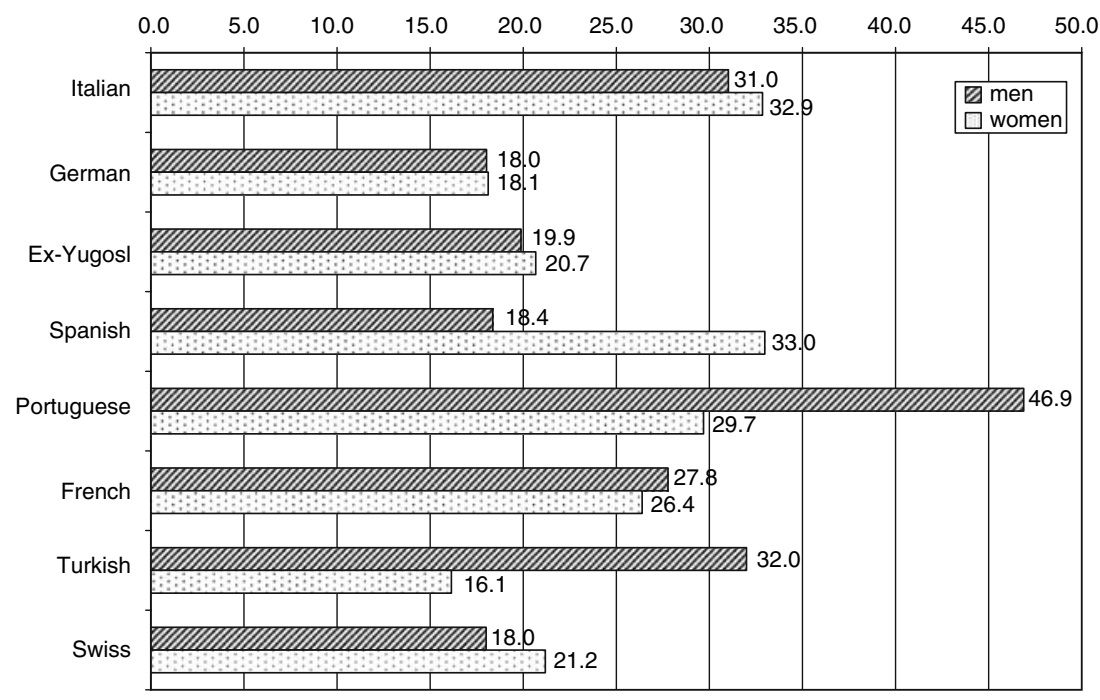

Lack of Mastery

Men

The reference group of Swiss men contained the lowest proportion of those reporting a lack of mastery, with similar proportions of men in the German, Spanish and Yugoslav group. Proportions reporting a lack of mastery were higher among Portuguese, Turkish and French men (see Fig. 3). The differences are significant at $p<0.001$.

\section{Women}

One in five women in the Swiss reference group, and similar proportions of German and Yugoslav women, reported a lack of mastery. Higher proportions of women reported lack of mastery in the Turkish, Italian and Portuguese groups, and slightly lower proportions in the French group $(p=0.001)$.

Lack of Physical Activity

Men

One in three men in the Swiss and German groups are physically inactive, i.e., they do not take part in any sporting activity during their leisure hours. Men in the Turkish, French, Portuguese, Spanish, Italian and Yugoslav group all reported higher proportions of physical inactivity (see Fig. 4). These differences are significant $(p<0.001)$.
Fig. 4 Frequency distributions of reported "lack of physical activity", by origin and sex (SHS 2002)

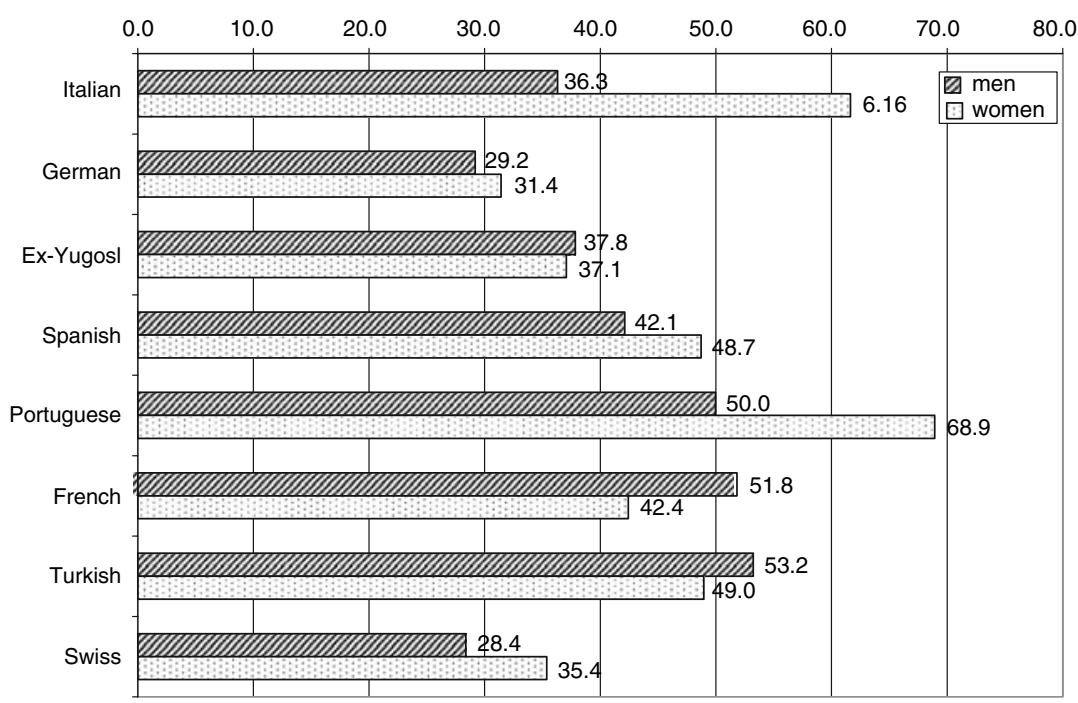




\section{Women}

One in three women in the Swiss reference groups, and a similar proportion of women from Former Yugoslavia, do not take part in any sporting activity during their leisure hours. The highest proportions of those not participating in any sport were found among the Portuguese, Italian, Turkish and Spanish groups. German women were the most likely to take part in sports. All these differences are statistically significant at a level of $p<0.001$.

Overweight $(\mathrm{BMI}>30)$

\section{Men}

According to the body mass index (BMI, calculated from the interviewees self-reported weight and size), nearly half of the Swiss men interviewed and a similar proportion of men from Former Yugoslavia were found to be overweight, Turkish, Portuguese, Italian and Spanish men reported higher proportions of overweight. There were fewer overweight men in the German and French groups (see Fig. 5). However, the differences were not statistically significant $(p=0.08)$.

\section{Women}

One in four Swiss women was found to be overweight (considerably fewer than among the Swiss men). There were fewer overweight women in the French group and none at all in the Turkish group. There were higher proportions of overweight women in the Italian, Portuguese,
Yugoslav and Spanish groups. These differences are significant $(p=0.001)$.

\section{Multivariate Analyses}

Logistic regression analyses were run on the health-related variables and fitted the model by including the following co-variates: nationality, age group, socio-demographic group, occupational group and income (cf. demographic characteristics, Table 1). In this section we comment on each of the seven immigrant groups and their respective odds ratios (OR) appearing in the logistic regression analyses. As a general remark, many of the differences found to be significant in the univariate analyses disappear in the multivariate analyses when controlled for the sociodemographic variables (Table 3 ).

\section{The Italian Group}

The OR measuring the association between health-related issues and Italian immigrants (both men and women) are significant in four out of the five health variables. Italian men and women were more likely to report suffering from chronic symptoms than the Swiss reference group. They were also more likely to report feeling mentally unwell, to feel a lack of mastery, and to take little exercise. The trend towards a higher proportion of overweight, when controlled for the other co-variates, is no longer significant. The Italian group shows the highest number of significant differences compared to the Swiss reference group.
Fig. 5 Frequency distributions of overweight (BMI > 30), by origin and sex (SHS 2002)

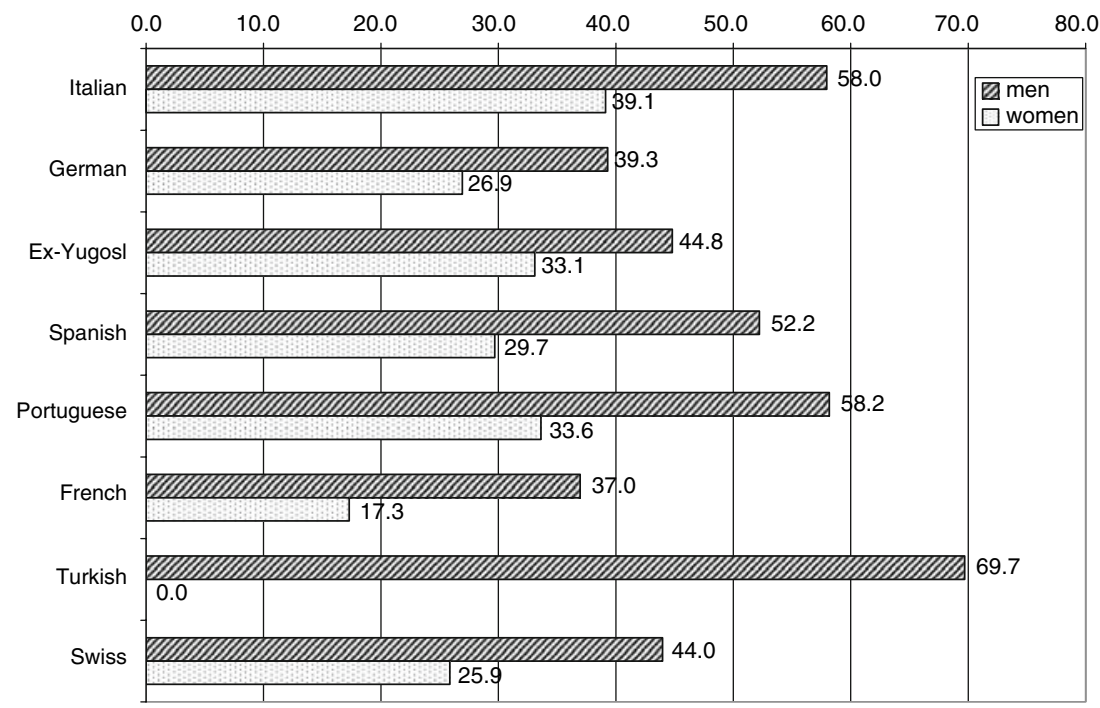


Table 3 Logistic regression analyses: association of health related variables and nationality, adjusted for age, education, socio-professional category and income (SHS 2002, $n=19,249$ )

\begin{tabular}{|c|c|c|c|c|c|c|c|}
\hline Symptoms & $\mathrm{OR}^{\mathrm{a}}$ & $95 \%$ C.I. $^{\mathrm{b}}$ & Sig. ${ }^{\mathrm{c}}$ & Symptoms & OR & 95\% C.I. & Sig. \\
\hline Men & & & & Women & & & \\
\hline Italian & 0.79 & $0.63-0.98$ & 0.03 & Italian & 0.66 & $0.50-0.87$ & $<0.001$ \\
\hline German & 0.89 & $0.65-1.22$ & 0.46 & German & 1.13 & $0.84-1.53$ & 0.42 \\
\hline Yugoslavian & 1.18 & $0.79-1.75$ & 0.42 & Yugoslavian & 1.20 & $0.81-1.78$ & 0.35 \\
\hline Spanish & 1.32 & $0.86-2.05$ & 0.21 & Spanish & 0.84 & $0.50-1.40$ & 0.50 \\
\hline Portuguese & 0.82 & $0.51-1.32$ & 0.42 & Portuguese & 0.73 & $0.44-1.21$ & 0.22 \\
\hline French & 0.84 & $0.52-1.35$ & 0.47 & French & 1.05 & $0.64-1.70$ & 0.86 \\
\hline Turkish & 1.03 & $0.49-2.19$ & 0.93 & Turkish & 0.61 & $0.26-1.40$ & 0.24 \\
\hline Lack of mental wellbeing & OR & 95\% C.I. & Sig. & Lack of mental wellbeing & OR & 95\% C.I. & Sig. \\
\hline Men & & & & Women & & & \\
\hline Italian & 1.32 & $1.02-1.71$ & 0.04 & Italian & 1.74 & $1.35-2.23$ & $<0.001$ \\
\hline German & 1.35 & $0.92-1.97$ & 0.13 & German & 1.15 & $0.82-1.62$ & 0.42 \\
\hline Yugoslavian & 1.03 & $0.61-1.74$ & 0.91 & Yugoslavian & 1.68 & $1.10-2.58$ & 0.02 \\
\hline Spanish & 0.57 & $0.29-1.11$ & 0.10 & Spanish & 1.98 & $1.24-3.15$ & 0.00 \\
\hline Portuguese & 1.07 & $0.62-1.86$ & 0.80 & Portuguese & 0.98 & $0.60-1.62$ & 0.95 \\
\hline French & 1.49 & $0.86-2.56$ & 0.15 & French & 0.97 & $0.55-1.73$ & 0.92 \\
\hline Turkish & 2.09 & $0.82-5.35$ & 0.12 & Turkish & 2.13 & $0.82-5.59$ & 0.12 \\
\hline Lack of Mastery & OR & 95\% C.I. & Sig. & Lack of Mastery & OR & 95\% C.I. & Sig. \\
\hline Men & & & & Women & & & \\
\hline Italian & 1.90 & $1.44-2.53$ & $<0.001$ & Italian & 1.89 & $1.39-2.57$ & $<0.001$ \\
\hline German & 1.00 & $0.64-1.57$ & 0.99 & German & 0.75 & $0.50-1.14$ & 0.18 \\
\hline Yugoslavian & 1.48 & $0.79-2.77$ & 0.22 & Yugoslavian & 0.98 & $0.51-1.88$ & 0.94 \\
\hline Spanish & 1.19 & $0.61-2.30$ & 0.61 & Spanish & 1.47 & $0.79-2.70$ & 0.22 \\
\hline Portuguese & 2.20 & $1.10-4.38$ & 0.03 & Portuguese & 1.32 & $0.74-2.36$ & 0.35 \\
\hline French & 1.64 & $0.91-2.97$ & 0.10 & French & 1.37 & $0.75-2.51$ & 0.31 \\
\hline Turkish & 0.99 & $0.27-3.65$ & 0.99 & Turkish & 0.83 & $0.23-3.03$ & 0.77 \\
\hline Lack of Physical activity & OR & 95\% C.I. & Sig. & Lack of Physical activity & OR & 95\% C.I. & Sig. \\
\hline Men & & & & Women & & & \\
\hline Italian & 1.50 & $1.20-1.88$ & 0.00 & Italian & 2.88 & $2.25-3.70$ & $<0.001$ \\
\hline German & 0.78 & $0.55-1.11$ & 0.17 & German & 0.67 & $0.49-0.91$ & 0.01 \\
\hline Yugoslavian & 1.54 & $0.99-2.38$ & 0.05 & Yugoslavian & 2.23 & $1.49-3.34$ & $<0.001$ \\
\hline Spanish & 1.76 & $1.10-2.84$ & 0.02 & Spanish & 3.35 & $2.09-5.36$ & $<0.001$ \\
\hline Portuguese & 2.06 & $1.27-3.34$ & $<0.001$ & Portuguese & 3.74 & $2.37-5.91$ & $<0.001$ \\
\hline French & 2.67 & $1.65-4.31$ & $<0.001$ & French & 1.95 & $1.22-3.12$ & 0.01 \\
\hline Turkish & 1.41 & $0.56-3.57$ & 0.46 & Turkish & 1.73 & $0.69-4.36$ & 0.24 \\
\hline $\mathrm{BMI}>30$ & OR & 95\% C.I. & Sig. & $\mathrm{BMI}>30$ & OR & 95\% C.I. & Sig. \\
\hline Men & & & & Women & & & \\
\hline Italian & 0.96 & $0.67-1.36$ & 0.80 & Italian & 1.27 & $0.88-1.83$ & 0.20 \\
\hline German & 0.94 & $0.54-1.65$ & 0.83 & German & 0.59 & $0.30-1.16$ & 0.13 \\
\hline Yugoslavian & 1.68 & $0.97-2.93$ & 0.07 & Yugoslavian & 1.19 & $0.61-2.33$ & 0.61 \\
\hline Spanish & 0.61 & $0.24-1.53$ & 0.29 & Spanish & 0.73 & $0.29-1.82$ & 0.49 \\
\hline Portuguese & 0.40 & $0.13-1.30$ & 0.13 & Portuguese & 1.45 & $0.71-2.95$ & 0.31 \\
\hline French & 1.23 & $0.56-2.73$ & 0.61 & French & 1.36 & $0.62-3.00$ & 0.44 \\
\hline Turkish & 1.61 & $0.61-4.28$ & 0.34 & Turkish & $<0.001$ & $<0.001-999.999$ & 0.96 \\
\hline
\end{tabular}

${ }^{\mathrm{a}}$ Odds Ratio; ${ }^{\mathrm{b}}$ Confidence Intervals; ${ }^{\mathrm{c}}$ Significance level 


\section{The German Group}

The German group is the second largest immigrant group in the sample and gives a different picture. In both men and women, no associations between nationality and health were found to be significant, with one exception: the OR of physical activity is significantly higher than in the Swiss reference group.

\section{People from Former Yugoslavia (of Serbian, Croatian, Bosnian, Kosovo, and Macedonian Origin)}

Men and women from Former Yugoslavia were less likely to be physical active in their leisure time than the Swiss, with significant OR. Yugoslav women were significantly more likely to feel mentally unwell. All other OR were below statistical significance.

\section{The Spanish Group}

The Spanish group shows almost identical patterns to the Yugoslav group: trends and the significance of the OR were the same both men and women as in the Yugoslavian group.

\section{The Portuguese Group}

For Portuguese men, two OR were less favourably associated: Portuguese men were more likely to report having less of a sense of mastery and were less likely to take part in sports. Portuguese women were less likely to take part in sports than the Swiss reference group.

\section{The French Group}

No OR measuring the associations between French nationality and health status were found to be significant, with one exception: the French women were less likely to take part in sports than the Swiss women.

\section{The Turkish Group}

No OR measuring the associations between Turkish nationality and health status were found to be significant, either in men or in women.

\section{Discussion}

Our study of the self-reported health of immigrant groups analysed data collected by the SHS in 2002 from 19,249 interviewees with Swiss, Italian, German, Yugoslav,
Spanish, Portuguese, French and Turkish nationality. Our findings provide evidence of a number of health disparities between Swiss people and immigrants, and between different immigrant groups. While the self-reported health status of what could be termed "Northern" immigrant groups (German and French) does not vary significantly from that of the Swiss, there are some differences in the self-reported health status of "Southern" immigrants. Physical activity (or the lack of it) is the one health issue where the differences are most significant among most immigrant groups.

These findings should, however, be interpreted with caution for several reasons. First, since a number of foreign nationals were a priori excluded from being interviewed (no telephone in the household, did not speak one of the three main Swiss languages, were not living in a private household), the sample sizes of some of the immigrant groups were too small to be representative of their respective immigrant groups in Switzerland. The exclusion of foreign language speakers from the survey means that recent arrivals, such as refugees and asylums seekers could not provide information on their self-reported health. Since evidence suggests that these immigrant population are especially vulnerable groups [13] and have often poor health status, our findings on self-reported health of immigrants would be more nuanced had there been a way to consider these groups as well.

A further limitation lies in the fact that the SHS questionnaire did not contain enough immigrant-specific questions, for example, on length of residence in Switzerland, nationality at birth etc. [14]. Thus, important information was missed about the extent to which different groups of immigrants are integrated in Switzerland.

Nevertheless, a number of our findings have potential relevance: The Italians are clearly an at-risk group since in all five variables (indices) worse outcomes were found in the Italian group, both women and men, than in the Swiss reference group. In relation to reported physical symptoms, there was a clear difference between the Swiss and the "Northern" immigrant groups, which were less likely to report symptoms, and the "Southern" groups, originating in the Southern (Mediterranean) countries, which were more likely to report symptoms. However, in the logistic regression analyses, only the differences between the Swiss and Italians remained significant. Our interpretation for this is that socio-economic status has a stronger influence on self-reported health than nationality and migration background [15].

Some researchers have described what has come to be known as the "healthy immigrant" effect, i.e., that immigrants are often healthier than the long-term residents of a country [16]. In our results we could find no evidence to defend this hypothesis. The data suggest that both 
immigrants and the majority Swiss population may suffer from chronic health problems. One explanation for this may be that Swiss migration policy has not, in the past, "selected" healthy immigrants. However, the length of time that the immigrant groups have been in Switzerland should have leveled out differences in health status between them and between them and the Swiss population.

Lack of physical activity was the one variable with the highest number of significant associations in the regression analyses. Interestingly, but not surprisingly, German origin was positively associated with physical activity, whereas in the other groups-Italians, Spaniards, Portuguese, Yugoslavs-there were negative associations. The living conditions of immigrants in Switzerland may partly explain these results: lower rates of physical activity of Portuguese, Yugoslavs and Spanish correlate with their socio-professional activity. These groups contains higher proportions of blue-collar workers; they are more likely to work in those sectors (construction, etc.) requiring physical exertion, and do not generally need to undertake additional physical activity (in terms of promoting their health) outside work hours.

As for mental health, feeling of lack of mastery was found more frequently among Italian and Portuguese men, and a lack of mental wellbeing was more marked among women from Italy, Spain, and Former Yugoslavia. On balance, this study suggests that health disparities between immigrants from Southern Europe and Swiss people exist.

The self-reported ill health of immigrant groups is an important pointer for health policies and planning. The reported health of "Southern" immigrant groups is inferior to that of the Swiss-at least with regard to the presence of physical symptoms and mental ill-health. If it is the position of the Swiss healthcare system to provide quality healthcare to all groups and to ensure equality health provision for all its residents, including immigrants, and to strive for equal health outcomes for all [17], epidemiological baseline data including self-reported ill health among is a useful basis for health planning.

One way to reduce health disparities among Switzerland's immigrant groups is to implement preventive medicine and public health interventions which reach out not only to the mainstream population but also to minority groups. This would include interventions that are context-sensitive (culturally sensitive) and targeted at particular immigrant groups, that is: those at risk in particular areas and contexts. An intervention study showed for example that by "cultural adaptations to contents and method of delivery" of a health education and physical exercise programme it was possible it was possible to improve mental health of elderly immigrants [18]. Also, these immigrant-specific interventions should be carried out in the immigrants' languages and in collaboration with mediators acquainted with the immigrants' context.

Our study also shows that there is no use in analyzing the data indiscriminately by using only a dichotomous variable "Swiss vs. immigrants". The possibility of differentiating by using different statistical techniques, according to migration context helps avoid stereotyping [19]. Further research, however, is needed, in order to pursue this process of differentiation; there should be health surveys in the languages spoken by the main immigrant groups, as well as qualitative and participatory research with immigrant people themselves.

Acknowledgments The BFS (Bundesamt für Statistik, Swiss Federal Statistical Office (www.bfs.admin.ch/) has provided the data used in this study.

\section{References}

1. Rausa F, Schläpfer M. Ausländerinnen und Ausländer in der Schweiz - Bericht 2005. Statistik der Schweiz, ed. BFS. Neuchâtel: Bundesamt für Statistik; 2005.

2. Loue S. Handbook of immigrant health. New York: Plenum Press; 1998.

3. Smedley BD, Stith AY, Nelson AR. Unequal treatment. Confronting racial and ethnic disparities in health care. Washington: The National Academies Press; 2003.

4. Fiscella $\mathrm{K}$ et al. Inequality in quality: addressing socioeconomic, racial, and ethnic disparities in health care. JAMA 2000; 283:2579-84.

5. Weiss R. Macht Migration krank? Eine transdisziplinäre Analyse der Gesundheit von Migrantinnen und Migranten. Zürich: Seismo; 2003.

6. Vranjes N, Bisig B, Gutzwiller F. Gesundheit der Ausländer in der Schweiz. Bern: Bundesamt für Gesundheit; 1996.

7. Bischoff A, Loutan L, Burgi D. Migration and health in Switzerland. Bern: BAG; 1997.

8. Bouchardy C, Wanner P, Raymond L. La mortalité des étrangers en 1989-92. Genève: ASRT; 2001.

9. BAG, Migration und Gesundheit: strategische Ausrichtung des Bundes - 2002-2006. Bundesamt für Gesundheit, Bundesamt für Flüchtlinge, Bundesamt für Ausländerfragen und Eidgenössische Ausländerkommission, Bern, 2002.

10. IHA-GfK, Schweizerische Gesundheitsbefragung SGB 2002 Schlussbericht zur Datenerhebung. Neuchâtel: Bundesamt für Statistik; 2003.

11. BFS, Schweizerische Gesundheitsbefragung: Gesundheit und Gesundheitsverhalten in der Schweiz 1997. Neuchâtel: BFS; 2000.

12. BFS, Pondération de l'Enquête Suisse sur la santé 2002, Bundesamt für Gesundheit. Neuchâtel: Sektion Gesundheit; 2003.

13. Loutan $L$ et al. Impact of trauma and torture on asylum seekers. Eur J Public Health 1999;9:93-6.

14. Bischoff A, Wanner P. Gesundheitsmonitoring für MigrantInnen: Sinnvoll? Machbar? Realistisch? Neuchâtel: Swiss Forum for Migration and Population Studies; 2004.

15. Newbold KB, Danforth J. Health status and Canada's immigrant population. Soc Sci Med 2003;57(10):1981-95. 
16. Muennig P, Fahs MC. Health status and hospital utilization of recent immigrants to New York City. Prev Med 2002;35(3):225-31.

17. WHO, Gesundheit 21. Gesundheit für alle, ed. W.R.f. Europa. Kopenhagen: Weltgesundheitsorganisation; 1998.

18. Reijneveld SA, Westhoff MH, Hopman-Rock M. Promotion of health and physical activity improves the mental health of elderly immigrants: results of a group randomised controlled trial among
Turkish immigrants in the Netherlands aged 45 and over. J Epidemiol Community Health 2003;57(6):405-11.

19. Wiking E, Johansson SE, Sundquist J. Ethnicity, acculturation, and self reported health. A population based study among immigrants from Poland, Turkey, and Iran in Sweden. J Epidemiol Community Health 2004;58(7):574-82. 